\title{
The Pioneer Work of the Systematist*
}

\section{By The Right Hon. Lord Rothschind, F.R.S.}

$\Gamma^{\mathrm{H}}$ HE inquiry into the secrets of organic Nature may be divided into three categories of questions: (1) what organisms creative forces have produced on earth; (2) how they have produced them; and (3) what is the nature of the creative forces. It was at the time of Linnæus a comparatively simple achievement for one man to have enumerated all the animals then known, his "Systema Naturæ" of 1758 containing altogether fewer than 4300 species. That task is in our days a hundred times more difficult, not only on account of the vast number of species which have poured into collections, are still pouring in and will continue to do so for a long time, but also because research in systematics requires a much deeper knowledge of the morphology and bionomics of the animals classified. At the time of Linnæus and after, when systematics were in their infancy, individual specimens showing marked differences were as a rule diagnosed as representing distinct species, the unit called species being looked upon as essentially a constant.

Experience has now furnished a guiding principle in the facts that similarity does not necessarily mean relationship of the forms under observation, that dissimilarity is not necessarily evidence of specific distinctness, and that variability obtains in every species and every organ; and if these facts are kept in mind by the system. atist, the reproach of superficiality often justly levelled at work in taxonomy can be borne with equanimity.

Variability is an essential character of everything alive. The concept of the constant species of former days is replaced by the concept of the flexible species, and the saying that like breeds like requires modifying into the statement that a population breeds a population with the same extent of variability. If like breeds like were being taken literally, we should have to alter it into like breeds unlike. For, strictly speaking, individuals are never alike whatever their relationship to each other. A calculation, for example, of the number of specimens required of the commonest British mouse-flea (Ctenophthalmus agyrtes) in order to find among them two absolutely alike in the number and position of the bristles on the body arrives at the amusing figure of many million billions, a figure certainly in excess of that of the whole flea-population of Great Britain, and tantamount to proving that there are no two specimens alike.

In studying the characteristics of each specific unit and drawing up diagnoses for purposes of recognition, the systematist renders service in two quite different spheres of work and thought. Being alone able to identify the species in the difficult

* From the presidential address to Section D (Zoology) of the British Association delivered at York on Sept. 1.

No. 3284 , Vol. 130$]$ group in which he specialises, he assists defensive biology in its task of safeguarding humanity against the ravages of health- or food-destroying organisms. Applied biology can only be a science if based on sound systematics. For example, when the Commission investigating bubonic plague in India had become definitely convinced that the plague was a rat disease transmitted to human beings through the agency of a particular species of rat-flea, no satisfactory explanation could be found why in Colombo and the city of Madras an outbreak of plague did not last long, although rats and rat-fleas abounded. The puzzle was solved when Dr. Hirst took the matter up and sent to my brother the flea material collected in the towns mentioned during a period when there was no plague and again when an outbreak occurred. The examination of the material proved that the flea ordinarily infesting rats at Colombo and at Madras was not (as the Commission had assumed) the plague-flea Xenopsylla cheopis, but X. astia, a very similar, but different species, which, by experiments, Dr. Hirst proved to be an inefficient carrier of the disease. When during the campaign in Mesopotamia camps became infested with rats, the British Museum could give the reassuring answer to an inquiry that there was no danger of a serious outbreak of plague, because the rat-fleas collected were $X$. astia, none belonging to $X$. cheopis.

The help which the systematist can extend to applied biology, however, is for him only a sideissue or a by-product; he is a student of pure science, devoting his time to the discovery of new species, of new connexions between them and of new facts bearing on the relation between the species and its surroundings, the driving force in this pursuit of knowledge being the irresistible attraction which the subject has for him.

The describing of new species and finding the right place for them in a given scheme of classification and the identifying of species may seem work of an elementary kind, necessary and useful, but nevertheless rather superficial. If systematics ended there, they might satisfy the collector perhaps, but scarcely the scientific mind. But this preliminary work is only a part of systematics. A natural classification is based on blood-relationship, and therefore entails an inquiry into the evolution of the species classified. Systematics change from a static study of form into a dynamic study of evolution. A species is like a book, which must be read critically and in its entirety. Unfortunately the systematist is much handicapped, as in the case of mammals, birds, insects and some other classes he has to be content with the portions of the animal which it is customary to preserve in collections. But even so, the contemplation of the skins and skulls of mammals, of the skins of birds, and of the dried insects reveals to him the 
latitude and the kind of variability and variation in the species of which he has adequate material, and enables him to compare results with the biologists who have studied the flexibility of species with the view of ascertaining whether the variability is purely fortuitous or whether there is system in the apparent confusion, many so-called laws of development having been discovered in the course of such inquiries.

Now, according to the experience of the systematist, such laws are rules with exceptions, sometimes the normal and the exceptional balancing each other, and it may be stated in general that the opposite must always be expected to occur. Exceptions have a certain fascination, not only for the writers of novels and plays, which are mostly based on exceptional characters or exceptional situations, but also for the biologist. As exceptions are comparatively rare, it requires large collections or long observation to discover them, and if there is no known exception to a certain rule of development, one has the feeling that it will some day be discovered. Take as an example the gallinaceous birds; among these game-birds are found the most striking instances of sexual dimorphism, the cocks exhibiting an often marvellous display of colours, as in the peacock, pheasants, fowls and others, the females being comparatively inconspicuous. It is therefore somewhat startling to find just in this order a genus in which the colours and behaviour of the sexes are reversed. In most species of the Oriental genus Turnix, a kind of quail, the females are larger than the males, bear a much brighter plumage, utter the call-note, fight each other for the possession of a male, and leave it to the male to incubate the eggs and to take care of the young.

Of the two classes of animals which I have studied more particularly, birds and Lepidoptera, the coloration is on the whole more constant in birds within the species at the same locality, apart from differences of sex and age, than in butterflies and moths, and individual di- and polymorphism is decidedly more common in the insects than in birds, but it is by no means absent among the latter. Dark and light phases long known to occur regularly among certain raptorial birds, for example, harriers, have during recent years been discovered to exist also here and there in other groups of birds, where they have formerly generally been described as distinct species. Such a correction had also to be made in the systematics of the American genus Rhamphocoelus, where red and yellow forms differing only in colour are now regarded as being individuals of one species, intermediate examples of an orange colour also being known, as well as very exceptional examples, such as the aberration Rhamphocoelus dunstalli Rothsch., in which the red and yellow colours extend to parts of the body other than those normally so coloured. The gaily coloured parrots furnish other examples of dichromotism; for example, the parakeet, Eos fuscata Blyth, which is a fairly common bird in New Guinea, appears in a red and a yellow form in the same place, both forms being about equally frequent, the red one slightly preponderating, and the lory Charmosyna stello Meyer, which appears in a black as well as a red form.

Besides colour and pattern, the size and shape of the specimens and their appendages and the structure of the secondary sexual characteristics of many kinds are found to be of great help in species classification, but experience has shown that none can be relied on unreservedly any more than colour or pattern. The comparison of the frequently exaggerated distinctions of the males, such as the horns of stags and beetles, the long forelegs of beetles, the stalked eyes of certain flies, etc., bas led to the discovery that the size of these organs is not always proportionate to the size of the body, but that the ratio in the development of such appendages increases disproportionately with the size of the specimens; in a small male of a species of Longicorn beetle the antenna may be a little longer than the body, while in a large specimen of the same species it may be several times longer than the body. Collections bear out this law of growth almost completely, but only almost. The stag-beetles are one of the families that have early directed attention to the remarkable development of their mandibles, which are sometimes so large, and the point of gravity therefore placed so far forward that the specimen has to assume a semi-erect position in order to keep its balance.

Such exceptions from general rules are of great interest, and it is therefore the duty of the systematist who comes across an exception-generally accidentally--fully to record it. Does it not seem evident from the cases mentioned that Nature can break a rule of development, just as Nature has created species and destroyed them? After all, the law is only our deduction based on the organisms we find provided by working methods of Nature we endeavour to discover. Circumstances may arise which interfere with the usual 'routine' of growth. The rule of growth illustrated by the stag-beetles, and corroborated by breeding of plants and animals, leaves no doubt that the characteristics in size and weight of an individual are not inherited and therefore are of no importance in the evolution of species. The test can be made in collections by comparing the closely related species of a genus with each other.

It must be clearly understood that in speaking of the unimportance for evolution of the bulk of individuals and the size of certain appendages, we referred to specimens of the same country, that is, individuals belonging to the same interbreeding population. In comparing the populations of two different countries the question assumes quite another aspect. In the systematics of birds the study of subspecies or geographical races has developed into a fine art. Size and shades of colour furnish the main distinctions between subspecies, and here we observe this important contrast that, while the difference of, say, $6 \mathrm{~mm}$. in the wing. lengths of specimens from the same country is of

$$
\text { No. 3284, VoL. 130] }
$$


no importance, because not inheritable, the difference of $2 \mathrm{~mm}$. between the populations of two countries is an inheritable quantity and therefore qualifies the two populations as being subspecifically distinct from one another. The evolution of the subspecific size-difference evidently starts with a shifting of the average size.

In our researches on the swallowtail butterflies we came across a combination of distinctions which is most instructive in an inquiry how the subspecies have come into existence. In a large number of species of butterflies and moths the geographical forms are separated by differences in the structure of the organs of reproduction and in colour and pattern. The important point is this, that the two sets of differences vary independently of each other within each subspecies.

The individual characters of the ancestral specimens do not influence the formation of the new race, only what is inheritable is of importance, and what is non-pathological and therefore adaptable to new and possibly less congenial surroundings.

Systematics and morphology are different expressions for the same kind of research, and I have no doubt that experimental biology will likewise have such a deepening influence on systematics that the superficial gap existing between the two lines of research will disappear too. Knowledge begins with the observation of phenomena, not with the experiment. The areas inhabited by the geographical forms of the species we have studied are either strictly separated, as in the case of island forms, or they are contiguous, there being between the areas no gap uninhabitable for the species, such as water would be for a dryland species, or a desert or savannah for a woodland species; or the areas may overlap. What happens when the areas touch or overlap and the geographical forms come in contact with one another? In a critical survey of the birds of Kenya Colony, lately published by Dr. van Someren in the Tring Museum periodical, ${ }^{1}$ every now and again the author records the observation that perfectly distinguishable subspecies intergrade in the intermediate district, where the two evidently have interbred and produced an impure population, not strictly distinguishable from, or identical with, either present subspecies. The phenomenon occurs very frequently, as must be expected ; for the breakingup of a species into geographical units cannot at once result in sexual aloofness. This, however, is a point which should be further investigated.

Not all geographical races amalgamate when they come together. Many of them have become so different that they can live side by side, each being an independent community not interbreeding with the other. Sometimes we find both amalgamation and specific distinctness among the forms divided from a parent stock, as is the case in the sister species cat-flea and dog-flea. The home of the genus Ctenocephalides to which both belong is Africa. Tropical and South Africa are inhabited

'Nor. Zool., 3\%, 292 ; 1932.

No. 3284, Vol. 130] by a subspecies with short head, and the Nile countries by one with a long head, the two intergrading in the Sudan and Uganda. From India to the Papuan countries, with the exclusion of Australia, a third race occurs, and in Europe and Central and North Asia the cat-fleas were represented by the flea occurring on dogs and wolves. When the Egyptian house-cat came to Europe, it brought with it the long-headed form of Ctenocephalides felis Bouché, which thereby came into contact with the palæarctic shortheaded dog-flea. One might have expected that they would hybridise and amalgamate, but they did not. The morphological differences are but slight, but a physiological barrier had arisen which kept and keep the catand dog-fleas as species, although they may occur together on the same individual of the host.

Systematics are not concerned with the study of species and their variations only. The species have to be grouped into genera and then into higher categories, all according to relationship, that is, according to descent. As in the study of subspecies the systematist must enter upon geography, so in the search for the past connexions between genera and families his research becomes linked with the past history of the earth and sometimes throws light on this history. If he can prove that two genera now widely separated geographic. ally are really of common stock, then there must have been a means of communication in former times which is now absent. If I may draw again on my brother's studies for an illustration, we will take the distribution of the queerest-looking fleas as yet discovered, the Australian Stephanocircus and the American Craneopsylla, in which the anterior portion of the head is divided off as a laterally compressed helmet. They are closely related, and the group originated in South America, where occur several allied genera and a genus connecting the group with more normally built fleas. They are only found in the Andesian countries from Patagonia to Ecuador (possibly occurring farther north), and in a modified form as Stephanocircus in Australia, nowhere else. The assumption that there was at one time a bridge between South America and Australia is the only explanation at all satisfactory. This conclusion is supported by another genus (or group of genera), Parapsyllus, which is plentifully represented by species in the same Andesian countries (not in eastern Brazil, the Amazons and Guianas), and recurs in one species on the islands in the South Polar Sea and in southern districts of Australia. The distribution of both genera evidently took place from west to east.

Although the systematist is primarily concerned with the organisms as produced by Nature, and not with the creative forces which have evolved them, his researches extend to so many different species that he is bound to collect evidence bearing on those forces and their working. There are, in fact, many questions which can only be answered with the help of extensive systematic collections. 